\title{
EFISIENSI TEKNIS USAHA PEMBESARAN LOBSTER DI PULAU LOMBOK, NUSA TENGGARA BARAT
}

\author{
TECHNICAL EFFICIENCY OF LOBSTER FARMING IN LOMBOK ISLAND, \\ WEST NUSA TENGGARA
}

\author{
Ervin Nora Susanti*), Rina Oktaviani**), Sri Hartoyo ${ }^{* *}$, dan Dominicus S. Priyarsono ${ }^{* *}$ \\ *) Program Studi Manajemen, Fakultas Ekonomi, Universitas Riau Kepulauan \\ Jl. Batu Aji Baru No 99 Batam, Kepulauan Riau 29425 \\ ${ }^{* *}$ Departemen Ilmu Ekonomi, Fakultas Ekonomi dan Manajemen, Institut Pertanian Bogor \\ Jl. Agatis, Kampus IPB Dramaga, Bogor 16680
}

\begin{abstract}
One aquaculture commodity that has a high economic value and potential to be developed in Indonesia is lobster. Lombok Island is a considerable lobster-producing area that has a great potential for the future development. However, lobster farming in this island lacks in productivity due to the management factors. Therefore, to achieve a sustainable development, the lobster farming needs a number of efforts to improve its productivity and technical efficiency. This study aims to: (1) analyze the influencing factors to the production of lobster farming and (2) analyze the level of technical efficiency and affecting factors on the technical inefficiency of lobster farming. The primary data were collected through surveys of 106 lobster-farming households. The stochastic frontier production function with Maximum Likelihood Estimator (MLE) method was used to analyze the efficiency of the cultivation system. The results suggested that most of the farmers are technically efficient with the average of the technical efficiency level of 0.91. The production inputs that have significant effects include the quantities of seed and feed and culture period. The technical inefficiency was influenced by the farmers' age, experience, education and perceptions on sustainability of their farming.
\end{abstract}

Keywords: technical efficiency, lobster farming, stochastic frontier production function, CobbDouglas, MLE

\begin{abstract}
Abstrak: Salah satu komoditas perikanan yang memiliki nilai ekonomis tinggi dan potensial untuk dikembangkan di Indonesia adalah lobster. Pulau Lombok merupakan salah satu daerah penghasil lobster yang memiliki potensi besar untuk dikembangkan. Namun demikian, produktivitas budidaya pembesaran lobster di Pulau Lombok masih rendah karena faktor manajemen. Sehingga diperlukan upaya peningkatan produktivitas dan efisiensi teknis untuk pengembangan budidaya pembesaran lobster yang berkelanjutan. Penelitian ini bertujuan (1) menganalisis faktor-faktor yang memengaruhi produksi usaha pembesaran lobster (2) menganalisis tingkat efisiensi teknis dan faktor yang memengaruhi inefisiensi teknis usaha pembesaran lobster. Data primer diambil melalui survei terhadap 106 rumah tangga pembudidaya lobster. Fungsi produksi stokastik frontier Cobb-Douglass dengan metode Maximum Likelihood Estimator (MLE) digunakan untuk menganalisis efisiensi pada masing-masing usaha pembesaran. Hasil analisis menunjukkan bahwa rata-rata pembudidaya adalah efisien secara teknis dengan rata-rata tingkat efisiensi teknis sebesar 0,91 . Input produksi yang memiliki pengaruh signifikan adalah jumlah bibit, pakan dan lama waktu budidaya. Faktor yang memengaruhi inefisiensi teknis adalah umur pembudidaya, pengalaman, pendidikan dan persepsi pembudidaya terhadap keberlanjutan usaha pembesaran lobster.
\end{abstract}

Kata kunci: efisiensi teknis, usaha pembesaran lobster, fungsi produksi stokastik frontier, Cobb-Douglas, MLE

${ }^{1}$ Corresponding author:

Email: ervin.nora@gmail.com 


\section{PENDAHULUAN}

Sektor Kelautan dan Perikanan (KP) menjadi salah satu sektor penggerak perekonomian dengan memberikan kontribusi pada Produk Domestik Bruto (PDB) Nasional tahun 2014 sebesar 3,25\% atau sebesar Rp342.7 trilyun (KKP, 2016). Salah satu komoditas perikanan yang memiliki nilai ekonomis tinggi dan potensial untuk dikembangkan di Indonesia adalah lobster. Perairan laut yang sangat luas dan baru dimanfaatkan 4,95\% untuk budi daya perikanan laut serta spesies bibit lobster yang banyak terdapat di laut Indonesia sangat mendukung untuk pengembangan budi daya lobster.

Lobster telah menjadi salah satu komoditas ekspor Indonesia. Nilai ekspor lobster Indonesia cenderung meningkat selama kurun waktu 2010 sampai dengan 2013, rata-rata sebesar 90\% (BPS, 2015). Dengan peningkatan ekspor tersebut berarti permintaan lobster di pasaran dunia cukup tinggi. Dekan demikian, peluang ekspor komoditas lobster masih menjanjikan. Namun, nilai ekspor dan kontribusi ekspor lobster terhadap total nilai ekspor Indonesia mengalami penurunan pada tahun 2014, jika dibandingkan 2013, dari $1,67 \%$ menjadi $0,92 \%$. Penyebab rendahnya nilai ekspor karena lobster yang diekspor berupa bibit yang dijual kepada negara yang membesarkan lobster seperti Vietnam (KKP, 2016).

Salah satu daerah penghasil lobster di Indonesia adalah Pulau Lombok, Nusa Tenggara Barat (NTB). Wilayah perairan laut yang ada di Pulau Lombok sangat potensial untuk pengembangan budi daya pembesaran lobster. Namun, usaha budi daya pembesaran lobster di Pulau Lombok masih tertinggal jika dibandingkan dengan usaha budi daya pembesaran lobster di Vietnam. Produktivitas usaha pembesaran lobster dalam karamba jaring apung yang rata-rata berukuran $3 \mathrm{~m}^{3}$ di Pulau Lombok diperkirakan adalah sebesar $50 \mathrm{~kg}$ per karamba (Priyambodo dan Sarifin, 2009) lebih rendah dibandingkan dengan produktivitas usaha pembesaran lobster di Vietnam yang mencapai $57,7 \mathrm{~kg}$ per karamba (Hung dan Tuan, 2009). Terdapat beragam tingkat survival pada usaha pembesaran lobster di Pulau Lombok, yaitu antara 50 sampai dengan $90 \%$. Sementara tingkat survival di Vietnam, dengan husbandry dan nutrisi yang bagus secara konsisten di atas 90\% (Priyambodo and Sarifin, 2009). Padahal lobster produksi Vietnam bibitnya banyak berasal dari Indonesia.
NTB merupakan salah satu eksportir bibit lobster yang besar di dunia, dimana pengiriman bibit lobster bisa mencapai 28.800 ekor per hari (DKP, 2015). Besarnya permintaan ekspor bibit lobster ini turut memengaruhi kegiatan budi daya pembesaran lobsterdi PulauLombok, banyak petani yang beralih menangkap bibit dan meninggalkan usaha budi daya. Menurut Priyambodo dan Sarifin (2009) penangkapan lobster ukuran kecil (bibit) bahkan kemudian menjadi segmen bisnis tersendiri di dalam rantai industri, setelah keberhasilan beberapa petani dalam melakukan pembesaran sampai dalam ukuran yang laku di pasar.

Berdasarkan kondisi bahwa nilai ekspor yang rendah, dan restocking maka pemerintah menerbitkan Peraturan Menteri Kelautan dan Perikanan Republik Indonesia Nomor 1/2015 (Permen-KP No.1/2015) tentang larangan penangkapan dan penjualan lobster (Panulirus sp.) dalam kondisi bertelur dan panjang karapas $<8 \mathrm{~cm}$ dengan berat minimal 200 gram. Pada tahun 2016 berat minimal menjadi 300 gram berdasarkan Surat Edaran Menteri Kelautan dan Perikanan N0 18/MEN-KP/ I/2015. Permen No.1/2015 tersebut justru dinilai kontra produktif dengan upaya pengembangan budi daya pembesaran lobster. Ketersediaan bibit untuk usaha budi daya secara legal menjadi sulit untuk didapatkan. Bibit di alam tidak bisa dimanfaatkan keberadaannya, padahal menurut hasil penelitian ACIAR, penangkapan bibit lobster di alam masih sustainable karena survival rate (SR) bibit di alam kurang dari 0,01\% (DKP, 2015). Bagi pelaku usaha lobster aturan tersebut justru dapat mematikan usaha pembesaran lobster sebagai akibat dari meningkatnya risiko produksi karena kemungkinan adanya faktor penyakit, cuaca dan iklim serta tuntutan untuk memenuhi kebutuhan hidup.

Disisilain, peningkatan permintaan lobsterdipasardunia menjadi peluang sekaligus tantangan bagi Indonesia untuk bisa meningkatkan kontribusinya memenuhi permintaan lobster dunia. Salah satu upaya yang bisa dilakukan adalah dengan meningkatkan produksi lobster melalui perluasan area karamba dan peningkatan produktivitas. Upaya peningkatan produktivitas dalam jangka pendek adalah melalui peningkatan efisiensi. Dalam jangka panjang peningkatan produktivitas dapat dilakukan melalui perubahan teknologi (Idiong, 2007). Faktor produksi yang efisien akan menciptakan produksi yang optimal (Mayashinta dan Firdaus, 2013). Oleh karena itu, penelitian terkait efisiensi pada usaha pembesaran lobster sangat penting untuk dilakukan dalam upaya meningkatkan produktivitas. Pengukuran 
efisiensi teknik pada tingkat usaha tani, mengidentifikasi faktor kunci yang dihubungkan dengan sistem produksi yang efisien, penilaian potensi dan sumber perbaikan dimasa mendatang merupakan hal yang penting untuk pengembangan akuakultur berkelanjutan (Sharma dan Leung, 2001). Peningkatan produktivitas lobster juga terkait dengan kemampuan pembudidaya dalam mengelola kegiatan usaha pembesaran lobster. Kemampuan tersebut terkait dengan karakteristik yang melekat pada diri pembudidaya. Selain itu persepsi pembudidaya terhadap keberlanjutan usaha juga ikut menentukan bagaimana pengelolaan usaha yang dilakukan oleh pembudidaya. Kemampuan mengelola usaha budi daya secara efisien dengan penggunaan input produksi yang tepat akan menentukan produktivitas yang dicapai.

Penelitian tentang efisiensi teknis pada berbagai usaha tani telah banyak dilakukan, seperti Lasmini et al. (2016) pada usahatani padi menggunakan Data Envelopment Analysis (DEA); Ningsih et al. (2015) pada usahatani kedelai menggunakan fungsi produksi stokastik frontier Cobb-Douglas dan regeresi tobit; Chen et al. (2015) pada usaha perikanan tangkap lobster menggunakan DEA; Crentsil dan Essilfie (2014) pada produksi perikanan nelayan kecil menggunakan fungsi produksi stokastik frontier Cobb-Douglas dan lainlain. Penelitian tentang efisiensi teknis ini dilakukan pada usahatani budi daya pembesaran lobster air laut.

Tujuan dari penelitian ini adalah menganalisis faktorfaktor yang memengaruhi produksi lobster di Pulau Lombok, menganalisis tingkat efisiensi teknis dan faktor-faktor yang memengaruhi inefisiensi teknis usaha pembesaran lobster di Pulau Lombok. Ruang lingkup penelitian ini adalah identifikasi faktor-faktor yang memengaruhi produksi lobster dan pengukuran efisiensi teknis usaha budi daya pembesaran lobster di Kecamatan Jerowaru, Kabupaten Lombok Timur Pulau Lombok, NTB.

\section{METODE PENELITIAN}

Penelitian dilakukan di Kabupaten Lombok Timur, Kecamatan Jerowaru, Desa Jerowaru: Dusun Telong Elong dan Desa Pare Mas: Dusun Gili Ree, Dusun Gili Belek, dan Dusun Ujung Batu Putee. Waktu penelitian dilakukan pada Bulan Oktober sampai dengan Desember 2015. Pemilihan lokasi penelitian dilakukan secara purposive dengan pertimbangan bahwa lokasi terpilih merupakan sentra usaha budi daya pembesaran lobster di Pulau Lombok.

Data yang digunakan pada penelitian ini adalah data primer yang dikumpulkan melalui survey pada 106 orang pembudidaya lobster. Pemilihan sampel dilakukan menggunakan teknik sampling snowball, hal ini dikarenakan jumlah populasi pembudidaya lobster sulit diketahui dengan pasti.

\section{Analisis Efisiensi Teknis}

Persamaan penduga fungsi produksi frontier CobbDouglas yang mengacu pada model Coelli et al. (1998) dari usaha pembesaran lobster dapat ditulis sebagai berikut:

$\ln Y=\beta_{0}+\beta_{1} \ln X_{1}+\beta_{2} \ln X_{2}+\beta_{3} \ln X_{3}+\beta_{4} \ln X_{4}+\beta_{5} \ln X_{5}+v_{i}-u_{i}$

Keterangan: Y (produksi lobster $\left(\mathrm{g} / \mathrm{m}^{3}\right)$ ); $\mathrm{X}_{1}$ (bibit lobster $\left.\left(\mathrm{ekor} / \mathrm{m}^{3}\right)\right) ; \mathrm{X}_{2}$ (pakan $\left.\left(\mathrm{kg} / \mathrm{m}^{3}\right)\right) ; \mathrm{X}_{3}$ (tenaga kerja $\left.\left(\mathrm{HKSP} / \mathrm{m}^{3}\right)\right) ; \mathrm{X}_{4}$ (lama waktu pembesaran (hari)); $\mathrm{X}_{5}$ (dummy spesies $(1=$ lobster mutiara, $0=$ lobster pasir)); $\beta_{0}$ (konstanta); $\beta_{\mathrm{j}}$ (koefisien parameter dimana $\mathrm{j}=1,2,3,4$, dan 5$) ; \mathrm{v}_{\mathrm{i}}-\mathrm{u}_{\mathrm{i}}\left(\right.$ error term $\left(\mathrm{u}_{\mathrm{i}}\right)$ efek inefisiensi teknis).

Pada persamaan tersebut nilai parameter yang diharapkan adalah positif $\left(\beta_{\mathrm{j}}>0\right)$. Untuk mengukur tingkat efisiensi teknis usaha budi daya lobster dapat menggunakan rumus sebagai berikut (Coelli et al. 1998):

$$
T E=\frac{E\left(Y / U_{i}, X_{1}, X_{2}, X_{3}, X_{4}, X_{5}\right)}{E\left(Y^{*} / U_{i}=0, X_{1}, X_{2}, X_{3}, X_{4}, X_{5}\right)}
$$

Keterangan: TE (efisiensi teknis); E (Y/ $\left.\mathrm{U}_{\mathrm{i}}, \mathrm{X}_{1}, \mathrm{X}_{2}, \mathrm{X}_{3}, \mathrm{X}_{4}, \mathrm{X}_{5}\right)$ (output observasi); dan $\mathrm{E}\left(\mathrm{Y}^{*} / \mathrm{U}_{\mathrm{i}}=\right.$ $0, X_{1}, X_{2}, X_{3}, X_{4}, X_{5}$ ) (output batas (frontier))

\section{Analisis Faktor Inefisiensi Teknis}

Dalam menentukan nilai parameter distribusi $\left(\mu_{\mathrm{i}}\right)$ efek inefisiensi teknis pada penelitian ini digunakan rumus sebagai berikut:

$$
\mu_{i}=\sigma_{0}+\sigma_{1} z_{1}+\sigma_{2} z_{2}+\sigma_{3} z_{3}+\sigma_{4} z_{4}+\sigma_{5} z_{5}+\sigma_{6} z_{6}+\omega_{i}
$$

Keterangan: $\mu_{\mathrm{i}}$ (efek inefesiensi teknis); $\mathrm{z}_{1}$ (umur pembudidaya (tahun)); $\mathrm{z}_{2}$ (pengalaman (tahun)); $\mathrm{z}_{3}$ (pendidikan (tahun)); $\mathrm{z}_{4}$ (jumlah tanggungan keluarga (orang)); $\mathrm{z}_{5}$ (dummy akses kredit ( $1=$ kredit, $0=$ tidak 
kredit)); $\mathrm{z}_{6}$ (indeks persepsi keberlanjutan, merupakan indeks komposit berdasarkan data skala likert merupakan pernyataan operasional untuk mengukur persepsi pembudidaya terhadap keberlanjutan usaha yang meliputi aspek sosial, ekonomi dan lingkungan. Penggunaan indeks komposit tersebut mengacu pada penelitian Ceyhan (2010), Gunduz et al. (2011) dan Waryanto (2015). Data skala likert yang merupakan skala ordinal ditransformasikan ke dalam skala interval menggunakan pendekatan Method of Succesive Interval (MSI)); Nilai koefisien yang diharapkan: $\delta 0>0, \delta 1>0$, $\delta 2, \delta 3, \delta 4, \delta 5, \delta 6<0$.

Proses produksi lobster yang merubah faktor input produksi menjadi output bertujuan menghasilkan output produksi yang tinggi. Upaya pencapaian tingkat produktivitas yang tinggi bisa dilakukan dengan pengelolaan kegiatan usaha secara efisien. Penggunaan faktor-faktor produksi secara optimal akan menentukan tingkat efisiensi usaha budi daya pembesaran lobster. Selain itu tingkat efisiensi juga ditentukan oleh karakteristik yang dimiliki oleh pembudidaya sebagai pelaku usaha. Karakteristik yang melekat pada diri pembudidaya akan menentukan kemampuannya mengelola dan mengambil keputusan pengalokasian faktor-faktor produksi secara efisien. Oleh karena itu, pada akhirnya pengelolaan usaha yang dilakukan secara efisien akan menentukan tingkat produktivitas usaha pembesan lobster. Alur kerangka pemikiran penelitian ini sebagaimana yang tersaji pada Gambar 1 .

\section{HASIL}

\section{Karakteristik Pelaku Usaha Pembesaran Lobster}

Jumlah responden pada penelitian ini adalah 106 orang yang terdiri dari 73 orang pembudidaya lobster pasir dan 33 orang pembudidaya lobster mutiara. Ratarata umur responden adalah 43 tahun, dengan lama pengalaman usaha rata-rata adalah 12 tahun. Rata-rata jumlah anggota keluarga 3 orang. Responden rata-rata memiliki tingkat pendidikan yang rendah, 29 orang responden tidak tamat $\mathrm{SD}$ dan 52 orang tamat SD, 18 orang tamat SMP dan 7 orang tamat SMA.

\section{Gambaran Umum Kegiatan Usaha Pembesaran Lobster}

Usaha budi daya pembesaran lobster di Pulau Lombok dilakukan dengan teknologi yang masih sangat sederhana. Terdapat dua spesies lobster yang dibudidayakan, lobster pasir (Panulirus homarus, sp) dan lobster mutiara (Panulirus ornatus, sp). Kedua jenis lobster tersebut merupakan spesies lobster yang dominan. Rata-rata penggunaan input produksi usaha pembesaran lobster selengkapnya sebagaimana tersaji pada Tabel 1. Bibit lobster yang berasal dari alam kemudian dibesarkan dalam karamba jaring apung. Ukuran karamba per petak rata-rata $21 \mathrm{~m}^{3}$. Pada fase awal pembesaran, sekitar 96 ekor bibit lobster di tebar pada karamba kecil berukuran sekitar 3,5 $\mathrm{m}^{3}$ sehingga padat penebaran awal yang diaplikasikan sekitar 27 ekor per $\mathrm{m}^{3}$. Setelah dipelihara selama tiga bulan, bibit lobster selanjutnya dipindahkan pada karamba yang berukuran lebih besar untuk dibesarkan hingga mencapai ukuran konsumsi yang diterima pasar. Ratarata padat penebaran pada fase pembesaran adalah 5 ekor lobster per $\mathrm{m}^{3}$. Padat penebaran ini relatif lebih rendah dari padat penebaran yang diaplikasikan oleh pembudidaya lobster di Vietnam. Menurut Mustafa (2013) padat penebaran lobster di Vietnam pada fase awal adalah 50-60 ekor per $\mathrm{m}^{3}$. Setelah dipelihara selama empat bulan bibit lobster dipindahkan di karamba pembesaran dengan padat penebaran sebanyak 5-8 ekor lobster per $\mathrm{m}^{3}$.

Input pakan yang digunakan pada usaha pembesaran lobster di Pulau Lombok adalah ikan rucah. Frekuensi pemberian pakan dilakukan sehari sekali pada waktu pagi sekitar pukul 9 sampai dengan pukul 10 WITA. Rata-rata penggunaan pakan adalah 21,6 kg per musim pembesaran. Pembudidaya tidak memiliki pedoman dalam hal penggunaan dosis pakan, karena pengenalan teknologi pemberian dosis pakan yang tepat belum pernah didapatkan. Dengan demikian, pemberian pakan hanya berdasarkan perkiraan saja. Pemberian pakan untuk lobster pada tiga bulan pertama pemeliharaan bervariasi antara $0,1-0,25 \mathrm{~kg}$ per hari. Pada fase pembesaran selanjutnya pemberian pakan adalah bervariasi antara $1-2,5 \mathrm{~kg}$ per hari. Cara pemberian pakan ini berbeda dengan cara yang dilakukan oleh pembudidaya lobster di Vietnam. Menurut Mustafa (2013) pemberian pakan pada lobster di Vietnam dilakukan dengan memperhitungkan bobot total lobster per hari. Secara periodik dilakukan pengukuran berat total lobster untuk menentukan 
jumlah pakan yang diberikan. Dosis pakan sebesar 15-20\% dari bobot total per hari diberikan pada 30 hari pertama pemeliharaan. Pada pemeliharaan 30-60 hari dosis pakan yang diberikan adalah 20-25\% dari bobot total per hari. Selanjutnya, dosis pakan yang diberikan adalah sebesar $10-17 \%$ dari bobot total per hari. Frekuensi pemberian pakan juga bergantung pada ukuran lobster. Lobster yang berukuran kecil $(<200$ gram) diberi pakan 2 kali per hari, sedangkan lobster berukuran besar (> 200 gram) diberi pakan 1 kali per hari. Pakan diberikan dalam jumlah yang lebih banyak (60-100 \%) pada sore atau malam hari menyesuaikan sifat nokturnal dari lobster yang aktif mencari makan pada malam hari.

Usaha pembesaran lobster tidak memerlukan tenaga kerja dalam jumlah yang banyak. Tenaga kerja dibutuhkan untuk pemberian pakan dan pembersihan karamba yang dilakukan rata-rata tiga hari sekali. Waktu yang dibutuhkan untuk pemberian pakan per hari bervariasi antara $0,5-2$ jam tergantung banyaknya karamba yang dimiliki. Jumlah tenaga kerja yang digunakan rata-rata adalah 0,84 hari kerja setara pria (HKSP) per $\mathrm{m}^{3}$. Lama waktu pembesaran lobster ratarata adalah 210 hari.

\section{Pendugaan Fungsi Produksi Stochatic Frontier}

Hasil pendugaan model fungsi produksi stokastik frontier dengan menggunakan metode MLE disajikan pada Tabel 2. Nilai parameter sigma-squared $\left(\sigma^{2}\right)$, menunjukkan total varians dari efek inefisiensi (ui) dan efek noise (vi). Hasil perhitungan diperoleh nilai $\sigma^{2}$ adalah sebesar 0,009 berbeda nyata pada tingkat $\alpha=5 \%$ sehingga dapat disimpulkan bahwa model yang digunakan sudah tepat dan kesalahan ui dan vi menyebar normal sesuai dengan asumsi yang diinginkan (Ojo et al. 2009). Hasil perhitungan nilai gamma $(\gamma)$, diperoleh hasil sebesar 0,003 dan tidak berbeda nyata pada tingkat $\alpha=5 \%$. Hal ini dapat diartikan pengaruh efek inefisiensi teknis tidak begitu dominan terhadap model yang dibangun. Namun, pengaruh noise seperti pengaruh iklim, serangan hama dan penyakit atau faktor lainnya yang lebih dominan. Adanya kesalahan model akibat noise pada proses produksi komoditas pertanian merupakan hal yang biasa terjadi dibandingkan dengan adanya pengaruh efek inefisiensi teknis (Kurniawan, 2008). Rendahnya nilai $\gamma$ juga ditemukan dalam penelitian Waryanto (2015).

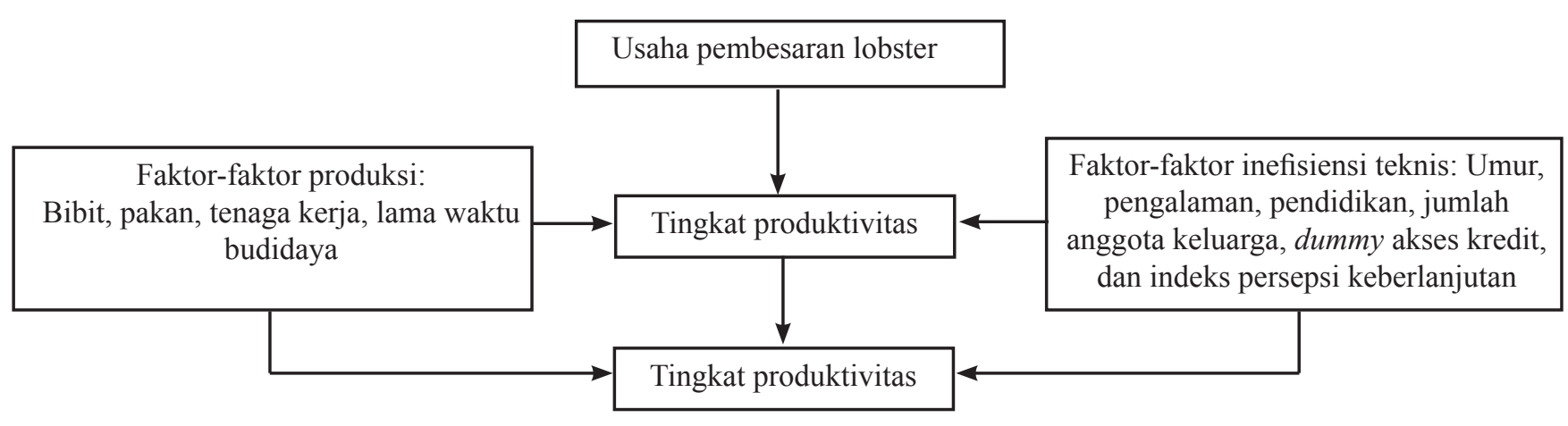

Gambar 1. Kerangka pemikiran penelitian

Tabel 1. Rata-rata penggunaan input produksi

\begin{tabular}{lccccc}
\hline & $\mathrm{N}$ & Minimum & Maksimum & Rata-rata & Std. Deviasi \\
\hline Produksi $\left(\mathrm{gram} / \mathrm{m}^{3}\right)$ & 106 & 556 & 1266 & 886,29 & 180,60 \\
Bibit $\left(\mathrm{lobster} / \mathrm{m}^{3}\right)$ & 106 & 3 & 6 & 5 & 0,86 \\
Pakan $\left(\mathrm{kg} / \mathrm{m}^{3}\right)$ & 106 & 9 & 35 & 21,60 & 6,46 \\
Tenaga kerja $\left(\mathrm{HKSP} / \mathrm{m}^{3}\right)$ & 106 & 0,35 & 2,50 & 0,84 & 0,37 \\
Lama waktu (hari) & 106 & 100 & 328 & 210,29 & 64,31 \\
\hline
\end{tabular}


Tabel 2. Hasil pendugaan fungsi produksi stochastic frontier usaha pembesaran Lobster

\begin{tabular}{lccc}
\hline \multicolumn{1}{c}{ Variabel } & Koefisien & Standar-error & t-ratio \\
\hline Konstanta & 4,86 & 0,27 & 17,94 \\
Bibit (X1) & $0,75^{*}$ & 0,08 & 8,49 \\
Pakan (X2) & $0,12^{*}$ & 0,06 & 2,10 \\
Tenaga kerja (X3) & 0,04 & 0,03 & 1,20 \\
Periode waktu (X4) & $0,09^{*}$ & 0,05 & 1,72 \\
Dummy spesies (X5) & $0,09^{*}$ & 0,03 & 2,64 \\
Sigma-square $\left(\sigma^{2}\right)$ & 0,009 & 0,001 & 7,22 \\
Gamma $(\gamma)$ & 0,003 & 0,06 & 0,04 \\
L-R test & & & 43,08 \\
\hline
\end{tabular}

Keterangan: *) nyata pada tingkat $\alpha=5 \%$

Nilai pendugaan parameter (parameter estimate) pada fungsi produksi stochastic frontier dapat menunjukkan nilai elastisitas dari input-input yang digunakan. Elastisitas fungsi produksi frontier untuk input yang berpengaruh nyata pada produksi lobster adalah jumlah bibit, pakan, lama waktu, dan dummy spesies (nyata pada tingkat $\alpha=5 \%$ ) secara berturut-turut adalah 0,75 ; 0,$12 ; 0,09$; dan 0,09. Apabila masing-masing input tersebut ditambah sebesar $1 \%$, ceteris paribus maka akan meningkatkan produksi lobster masing-masing sebesar $0,75 \% ; 0,12 \% ; 0,09 \%$; dan $0,09 \%$.

Variabel input jumlah bibit memiliki pengaruh positif yang terbesar pada produksi lobster. Penambahan input bibit sebesar $1 \%$ akan meningkatkan produksi lobster sebesar $0,75 \%$. Padat penebaran bibit lobster yang diaplikasikan di daerah penelitian relatif lebih kecil dibandingkan dengan padat penebaran lobster di Vietnam. Pada fase awal padat penebaran bibit lobster adalah 27 ekor per $\mathrm{m}^{3}$, pada fase pembesaran selanjutnya padat penebaran adalah 5 ekor per $\mathrm{m}^{3}$. Padat penebaran bibit masih perlu ditambah untuk meningkatkan produksi. Kematian bibit lobster pada fase awal pembesaran adalah tinggi salah satunya adalah karena sifat kanibalisme antar lobster. Untuk mengurangi risiko tersebut maka penambahan bibit lobster perlu dilakukan. Kendala yang dihadapi dalam usaha pembesaran lobster adalah ukuran padat tebar bibit yang sesuai untuk kegiatan pendederan maupun pembesaran lobster belum diketahui secara pasti. Padat penebaran bibit lobster di daerah penelitian masih lebih sedikit dibandingkan dengan padat penebaran bibit di Vietnam yang mencapai 50-60 ekor per $\mathrm{m}^{3}$ pada fase awal, dan 5-8 ekor per $\mathrm{m}^{3}$ pada fase pembesaran selanjutnya. Penelitian Cokrowati et al. (2013) menyimpulkan bahwa tingkat keberhasilan hidup lobster yang paling tinggi adalah pada padat penebaran bibit lobster 20 ekor per $\mathrm{m}^{2}$.

Pakan memberikan kontribusi positif dan signifikan untuk meningkatkan produksi lobster namun kontribusinya relatif lebih kecil dibandingkan kontribusi input bibit. Pakan yang digunakan di daerah penelitian adalah ikan rucah. Menurut Suastika et al. (2008); Priyambodo dan Sarifin (2009) penggunaan pakan berupa ikan rucah tidak ideal untuk pertumbuhan lobster, karena kurangnya kandungan gizi dan bisa menghasilkan pigmentasi pucat pada lobster dewasa. Kecilnya kontribusi pakan bisa disebabkan karena minimnya teknologi pemberian pakan yang dimiliki oleh pembudidaya. Pembudidaya tidak memiliki pedoman dalam hal pemberian dosis dan jenis pakan yang tepat untuk lobster. Teknologi terkait pemberian pakan yang tepat belum pernah didapatkan oleh pembudidaya. Sehingga selama ini pemberian pakan hanya dilakukan berdasarkan perkiraan pribadi saja. Pemberian pakan dilakukan dengan frekuensi sehari satu kali dengan tiga bulan pertama pemeliharaan dosis pakan bervariasi. Dosis pemberian pakan berbeda dengan yang dilakukan oleh pembudidaya lobster di Vietnam yang memperhitungkan bobot total lobster per hari untuk penentuan frekuensi, dosis dan komposisi pakan. Penambahan pakan akan meningkatkan produksi lobster, namun hal ini perlu diimbangi dengan adanya teknologi yang tepat terkait frekuesi, dosis dan komposisi jenis pakan. Pakan yang hanya berupa ikan rucah selain tidak ideal karena rendahnya kandungan gizi juga berpotensi menimbulkan penyakit karena sisa pakan yang tertinggal di karamba bisa mendatangkan parasit yang merugikan bagi pertumbuhan lobster. 
Penambahan tenaga kerja tidak signifikan meningkatkan produksi lobster. Usaha pembesaran lobster tidak bersifat labor intensif sehingga tidak dibutuhkan tenaga kerja dalam jumlah yang banyak. Tenaga kerja hanya diperlukan secara kontinu dalam hal pemberian pakan dan pembersihan karamba, selebihnya tenaga kerja dibutuhkan di awal persiapan pembuatan karamba dan panen. Dalam pemberian pakan dibutuhkan waktu bervariasi sekitar 1-2 jam dengan 1-2 orang tenaga kerja tergantung luasan karamba yang dimiliki. Penggunaan input tenaga kerja di daerah penelitian rata-rata hanya 0,8 HKSP per $\mathrm{m}^{3}$.

Variabel lamawaktupembesaran berpengaruh signifikan pada produksi lobster. Lobster pasir menjadi dewasa pada bobot 200 gram sampai 300 gram, sedangkan lobster mutiara baru dewasa setelah bobot jauh di atas $1 \mathrm{~kg}$ (Priyambodo and Sarifin, 2009). Untuk mencapai ukuran 150 gram, lobster pasir memerlukan waktu satu tahun sedangkan lobster mutiara 8 sampai dengan 9 bulan (Suastika et al. 2008). Rata-rata lama waktu pembesaran lobster di Pulau Lombok adalah 210 hari (7 bulan) dengan rata-rata ukuran lobster yang dipanen adalah 188 gram. Hal ini berarti lobster dipanen lebih cepat dengan bobot dibawah ukuran dewasa. Sehingga tambahan lama waktu pembesaran pada lobster akan berpengaruh nyata meningkatkan produksi lobster. Penambahan waktu tersebut dalam jangka panjang perlu diimbangi dengan teknologi penanganan penyakit pada lobster. Menurut responden di lapangan, lobster di atas ukuran 200 gram sangat rentan terkena penyakit. Sehingga untuk memenuhi bobot minimal 300 gram untuk bisa dijual secara legal sebagaimana aturan Surat Edaran Menteri Kelautan dan Perikanan No 18/ MEN-KP/I/2015 masih sulit untuk bisa dipenuhi oleh pembudidaya lobster. Sementara teknologi penanganan penyakit pada lobster belum pernah didapatkan oleh responden, sehingga mereka cenderung memanen lobster lebih cepat untuk menghindari risiko penurunan kualitas atau kematian lobster akibat serangan penyakit. Selama ini jika terjadi penyakit pada lobster, responden hanya mengambil lobster yang terjangkit penyakit tersebut tanpa ada solusi untuk mengatasi serangan penyakit yang ada. Variabel dummy spesies berpengaruh positif dan signifikan terhadap produksi lobster. Penambahan lobster mutiara sebesar $1 \%$ akan meningkatkan produksi lobster sebesar 0,09\%.

\section{Tingkat Efisiensi Teknis Usaha Pembesaran Lobster}

Distribusi efisiensi teknis yang diperoleh berkisar dari 0,73 sampai dengan 0,99 dengan tingkat efisiensi teknis rata-rata sebesar 0,91 (Tabel 3). Berdasarkan tingkat efisiensi teknis rata-rata yang diperoleh menunjukkan bahwa usaha pembesaran lobster di Pulau Lombok pada teknologi yang ada saat ini dikategorikan efisien secara teknis karena menghasilkan nilai dugaan yang lebih dari 0,7 sebagai batas efisien (Coelli, 1998). Pembudidaya yang berada pada tingkat efisiensi rata-rata masih mempunyai kesempatan $8,08 \% \quad(1-0,91 / 0,99 * 100)$ untuk meningkatkan produksinya. Dalam jangka pendek pencapaian produksi maksimal bisa dilakukan dengan mempertimbangkan faktor-faktor yang memengaruhi efisiensi teknis. Dalam jangka panjang peningkatan produksi bisa dilakukan melalui perubahan teknologi. Perubahan teknologi yang dibutuhkan dalam usaha pembesaran lobster adalah teknologi tentang pakan. Tidak hanya menyangkut ketepatan pemberian dosis pakan, tetapi juga teknologi tentang pakan alternatif yang memiliki kandungan nutrisi yang tepat untuk lobster. Selain itu dalam jangka panjang diperlukan teknologi terkait penanganan penyakit pada lobster.

Masih terdapatnya perbedaan tingkat efisiensi teknis yang dicapai pembudidaya di lokasi penelitian disebabkan karena adanya perbedaan kemampuan manajerial pembudidaya dalam mengelola usaha pembesaran lobster. Perbedaan kemampuan manajerial tersebut terkait erat dengan karakteristik yang melekat pada diri pembudidaya seperti umur, pengalaman dan pendidikan.

Tabel 3. Tingkat efisiensi teknis usaha pembesaran lobster

\begin{tabular}{lcc}
\hline $\begin{array}{l}\text { Tingkat efisiensi teknis } \\
(\%)\end{array}$ & $\begin{array}{c}\text { Jumlah } \\
\text { responden }\end{array}$ & Persentase \\
\hline$<70$ & 0 & 0 \\
$71-80$ & 9 & 8 \\
$81-90$ & 40 & 38 \\
$91-100$ & 57 & 54 \\
Total & 106 & 100 \\
\hline Maksimum & \multicolumn{3}{c}{0,99} \\
\hline Minimum & 0,73 \\
\hline Rata-rata & \multicolumn{3}{c}{0,91} \\
\hline
\end{tabular}


Faktor-faktor yang Memengaruhi Inefisiensi Teknis

Faktor-faktor yang memengaruhi inefisiensi teknis untuk usaha pembesaran lobster disajikan pada Tabel 4. Umur dan pengalaman pembudidaya lobster berpengaruh negatif dan nyata (pada tingkat $\alpha=5 \%$ ) terhadap inefisiensi teknis usaha pembesaran lobster. Hal ini berarti pembudidaya yang lebih tua dan berpengalaman lebih efisien secara teknis dibandingkan yang lebih muda dan kurang berpengalaman. Umur menangkap pengalaman pembudidaya yang mungkin terakumulasi dari waktu ke waktu karena belajar sambil bekerja (Jamal et al. 2016). Pembudidaya lobster yang lebih tua menjadi lebih mahir dengan teknologi berdasarkan akumulasi pengetahuan dan keterampilan yang didapatkan.

Pendidikan bisa merubah kebiasaan dan pola pikir. Petani dengan tingkat pendidikan yang lebih tinggi akan lebih terbuka dalam menerima informasi dan perubahan teknologi untuk meningkatkan efisiensi (Kusnadi et al. 2011 dan Alam et al. 2012). Pendidikan mempertajam kemampuan manajerial petani dalam mengambil keputusan yang tepat, memanfaatkan informasi yang baik sehingga meningkatkan efisiensi (Fadwiwati, 2013). Dalam penelitian ini, tingkat pendidikan berpengaruh nyata menurunkan inefisiensi teknis.

Variabel akses kredit pada penelitian ini tidak berpengaruh nyata terhadap inefisiensi teknis pada usaha pembesaran lobster. Hal ini disebabkan karena kredit yang diperoleh tidak semua digunakan untuk modal usaha pembesaran lobster, melainkan juga untuk memenuhi kebutuhan hidup yang lain diluar usaha pembesaran lobster. Variabel jumlah tanggungan keluarga juga tidak berpengaruh nyata terhadap inefisiensi teknis.

Variabel indeks persepsi keberlanjutan pelaku usaha pembesaran lobster berpengaruh negatif dan nyata (pada tingkat $\alpha=5 \%$ ) terhadap inefisiensi teknis. Semakin baik persepsi pembudidaya terhadap keberlanjutan usaha pembesaran lobster akan memengaruhi cara mengelola usaha sehingga akan mengurangi inefisiensi teknis. Apabila petani memiliki persepsi baik terhadap pembangunan pertanian berkelanjutan, maka pada akhirnya akan membantu pemerintah untuk mengimplementasikan konsep pembangunan berkelanjutan di tingkat lapang (Waryanto, 2015). Hiariey dan Romeon (2013) menemukan hubungan positif antara persepsi masyarakat terhadap partisipasi dalam pengelolaan kawasan pesisir Teluk Ambon Dalam (TAD). Semakin tinggi persepsi masyarakat maka semakin tinggi tingkat partisipasi terhadap pengelolaan kawasan pesisir TAD.

\section{Implikasi Manajerial}

Implikasi manajerial bagi petani untuk meningkatkan efisiensi secara teknis adalah perlu meningkatkan pengalaman dan pengetahuan tentang usaha budi daya lobster melalui pendidikan nonformal seperti pelatihan maupun menggali informasi dari berbagai media. Di samping itu persepsi petani terhadap keberlanjutan usaha juga perlu ditingkatkan sehingga akan memperbaiki cara pengelolaan usaha yang selama ini dilakukan.

Tabel 4. Hasil pendugaan parameter efek inefisiensi teknis fungsi produksi stochastic frontier usaha pembesaran lobster

\begin{tabular}{lccc}
\hline \multicolumn{1}{c}{ Variabel } & Parameter estimate & Standar error & t-ratio \\
\hline Konstanta & 0,65 & 0,18 & 3,68 \\
Umur & $-0,12^{*}$ & 0,04 & $-2,74$ \\
Pengalaman & $-0,06^{*}$ & 0,02 & $-3,54$ \\
Pendidikan & $-0,03^{*}$ & 0,02 & $-1,82$ \\
Jumlah tanggungan keluarga & $-0,01$ & 0,02 & $-0,61$ \\
Dummy akses kredit & 0,02 & 0,03 & 0,91 \\
Indeks persepsi keberlanjutan usaha & $-0,12^{*}$ & 0,06 & $-2,07$ \\
\hline
\end{tabular}




\section{KESIMPULAN DAN SARAN}

\section{Kesimpulan}

Produksi lobster di Pulau Lombok dipengaruhi oleh variabel input jumlah bibit, pakan, lama waktu pembesaran dan dummy spesies. Input jumlah bibit memiliki pengaruh positif yang terbesar pada produksi lobster. Pakan yang berupa ikan rucah memberikan kontribusi relatif lebih kecil dibandingkan dengan bibit untuk meningkatkan produksi lobster. Tambahan waktu budi daya hingga mencapai ukuran bobot dewasa akan meningkatkan produksi lobster, selama ini lobster dipanen lebih cepat dengan bobot dibawah ukuran dewasa

Pada tingkat teknologi yang ada saat ini, usaha pembesaran lobster di Pulau Lombok secara teknis sudah efisien. Dengan rata-rata tingkat efisiensi teknis sebesar 0,91. Faktor umur, pengalaman, pendidikan dan persepsi pembudidaya terhadap keberlanjutan usaha berpengaruh nyata terhadap inefisiensi usaha pembesaran lobster. Variabel akses kredit dan jumlah tanggungan keluarga tidak berpengaruh nyata terhadap inefisiensi usaha pembesaran lobster.

\section{Saran}

Penambahan jumlah bibit lobster dan perluasan areal budi daya lobster perlu dilakukan karena variabel bibit berpengaruh besar terhadap peningkatan produksi. Potensi perairan laut di Pulau Lombok sangat sesuai dan masih sangat layak untuk ekstensifikasi usaha budi daya pembesaran lobster. Untuk meningkatkan produksi dalam jangka panjang, diperlukan perubahan teknologi terutama adalah teknologi pemberian pakan yang tepat untuk lobster yang bisa menjadi substitusi penggunaan ikan rucah yang tidak ideal dan stoknya sangat tergantung musim. Pemerintah juga perlu meningkatkan peran penyuluh untuk memberikan pembinaan kepada pembudidaya, terutama terkait dengan bagaimana mengatasi masalah penyakit pada lobster.

Pemerintah perlu meninjau kembali pelaksanaan regulasi Permen KP No 1/2015 terkait larangan penangkapan bibit untuk kepentingan pengembangan usaha budi daya lobster. Hal ini untuk menjamin legalitas ketersediaan bibit yang diperlukan dalam pengembangan usaha budi daya. Selain itu perlu juga ditinjau ulang peraturan batas berat minimal lobster sebesar 300 gram untuk diperdagangkan yang mulai berlaku tahun 2016. Pada pelaksanaannya hal itu sulit dipenuhi oleh pembudi daya, mengingat semakin tingginya risiko kematian yang harus ditanggung karena lobster di atas ukuran 200 gram rentan dengan serangan penyakit, sulitnya pemenuhan kebutuhan pakan lobster, serta kemungkinan risiko dari pengaruh faktor alam yang lain. Terlebih teknologi yang memadai terkait pakan dan penanganan penyakit pada lobster belum didapat oleh pembudidaya.

\section{DAFTAR PUSTAKA}

Alam A, Hajime K, Ichizen M, Akira I, Esham M, Faridullah. 2012. Technical efficiency and its determinants in potato production: evidence from northern areas in gilgit-baltistan region of Pakistan. International Journal of Research in Management, Economic and Commerce (IJRMEC) 2 (3):1-17.

Coelli TJ, Rao DSP, Battese GE. 1998. An Introduction to Efficiency and Productivity Analysis. Boston: Kluwer-Nijhoff. https://doi.org/10.1007/978-14615-5493-6.

Ceyhan V. 2010. Assesing the agricultural sustainability of conventional farming systems in Samsun Province of Turkey. African Journal of Agricultural Research 5(13): 1572-1583.

Chen L, Gupta R, Mukherjee Z, Wanke P.2015. Technical efficiency of connecticut long island sound lobster fishery: a nonparametric approach to aggregate frontier analysis. Working Paper Series. University of Pretoria.

Cokrowati N, Utami P, Sarifin. 2013. Perbedaan padat tebar terhadap tingkat pertumbuhan dan kelangsungan hidup post peurulus lobster pasir (Panulirus homarus,sp) pada bak terkontrol. Jurnal Kelautan 5(2) : 156-166.

Crentsil C, Essilfie FL. 2014. Measurement of technical efficiency of smallholder fish production in Ghana : a stochastic frontier approach. Journal of Development and Agricultural Economics 6(5): 203-211. https://doi.org/10.5897/JDAE12.146.

[DKP] Dinas Kelautan dan Perikanan Provinsi Nusa Tenggara Barat. 2015. Kajian/Analisis Pengelolaan Benih Lobster (Panulirus, sp) Di Provinsi Nusa Tenggara Barat. Mataram: Dinas Kelautan dan Perikanan Provinsi Nusa Tenggara Barat.

Fadwiwati AY. 2013. Pengaruh penggunaan varietas 
unggul terhadap efisiensi, pendapatan dan distribusi pendapatan petani jagung di Provinsi Gorontalo [Disertasi]. Bogor: Institut Pertanian Bogor.

Gunduz O, Ceyhan V, Erol E, Ozkaraman F. 2011. An evaluation of farm level sustainability of apricot farm in Malatya Province of Turkey. Journal of Food, Agriculture \& Environment 9 (1): 700705.

Hung LV, Tuan LA. 2009. Lobster Seacage Culture in Vietnam. Australian Centre for International Agricultural Research Prosiding.

Hiariey, L.S., Romeon, N.R. 2013. Peran serta masyarakat pemanfaat pesisir dalam pengelolaan wilayah Pesisir Teluk Ambon Dalam. Jurnal Matematika, Sains, dan Teknologi 14(1): 48-61.

Idiong. 2007. Estimation of farm level technical efficiency in small scale swamp rice production in Cross River State of Nigeria: a stochastic frontier approach. World Journal of Agricultural Sciences 3(5):653-658.

Jamal E, Dewi YA. 2009. Technical efficiency of land tenure contracts in West Java Province, Indonesia. Asian Journal of Agriculture and Development 6(2): 21-33

[KKP] Kementerian Kelautan dan Perikanan. 2016. Informasi Kelautan Perikanan. Jakarta: Kementerian Kelautan dan Perikanan.

Kusnadi N, Tinaprilla N, Susilowati SH, Purwoto A. 2011. Analisis efisiensi usaha tani padi di beberapa sentra produksi padi di Indonesia. Jurnal Agro Ekonomi 29(1): 25-48. https://doi. org/10.21082/jae.v29n1.2011.25-48.

Kurniawan AY. 2008. Analisis efisiensi ekonomi dan daya saing usaha tani jagung pada lahan kering di Kabupaten Tanah Laut Kalimantan Selatan [tesis]. Bogor: Sekolah Pascasarjana, Institut Pertanian Bogor.

Lasmini F, Nurmalina R, Rifi A. 2016. Efisiensi teknis usaha tani padi petani peserta dan petani non peserta program SL-PTT di Kabupaten Sukabumi. Jurnal Manajemen \& Agribisnis 13(1): 59-68. https://doi.org/10.17358/
JMA.13.1.59.

Mayashinta W, Firdaus M. 2013. Faktor-faktor yang memengaruhi total factor productivity industri pertanian indonesia periode 1981-2010. Jurnal Manajemen \& Agribisnis 10(2): 90-97.

Mustafa A. 2013. Budi daya lobster (Panulirus sp.) di Vietnam dan aplikasinya di Indonesia. Media Akuakultur 8(2): 73-84.https://doi.org/10.15578/ ma.8.2.2013.73-84.

Ningsih IM, Dwiastuti R, Suhartini. 2015. Determinan efisiensi teknis usaha tani kedelai. Jurnal Manajemen \& Agribisnis 12(3): 216-225. https://doi.org/10.17358/JMA.12.3.216.

Ojo MA, Mohammed US, Ojo AO, Olaleye RS. 2009. Return to scale and determinants of farm level technical inefficiency among small scale yam based farmers in niger state, nigeria: implication for food security. International Journal of Agricultural Economics and Rural Development 2(1): 43-51.

Priyambodo B, Sarifin. 2009. Lobster aquaculture industry in Eastern Indonesia: present status and prospects. In: Spiny lobster aquaculture in the Asia-Pacific region. Proceedings of an international symposium, Nha Trang, Vietnam, 9-10 December 2008. ACIAR P No.132 pp.3645.

Sharma KR, Leung P. 2001. Technical Efficiency of Carp Pond Culture in South Asia : An Application of a Stochastic Meta-Production Frontier Model. Economics and Management of Shrimp and Carp Farming in Asia : A Collection of Research Papers Based on The ADB/NACA Farm Performance Survey. Bangkok: Network of Aquaculture Centers in Asia-Pasific.

Suastika M, Sukadi F, Surahman A. 2008. Improving Lobster Grow-Out and Nutrition in Nusa Tenggara Barat - a Feasibility Study. ACIARSADI Final Report. Canberra: ACIAR.

Waryanto B. 2015. Analisis keberlanjutan usaha tani bawang merah di Kabupaten Nganjuk Jawa Timur [disertasi]. Bogor:Institut Pertanian Bogor. 